\title{
On Current Situation and Development Prospect of the journalism \& mass communication education
}

\author{
Xiaojing Zhang \\ College of Media \& Communication, Wuhan Textile University, Wuhan 430073, P.R. China \\ wangyunli002@163.com
}

\begin{abstract}
Keywords: journalism \& mass communication education, academic research, discipline identity, media literacy.
\end{abstract}

\begin{abstract}
This document demonstrates that current situation and development prospect of the journalism \& mass communication education. There are three essential issues in present journalism \& mass communication education to confront: the balance between theory and practice, discipline identity, globalization influence. The journalism\& mass communication education and academic research complement each other. In future, it sums up briefly for outlets in dealing properly three relations: theory and practice, globalization and localization, and convergence and innovation.
\end{abstract}

\section{Introduction}

The journalism \& mass communication education is closely connected with the development of the society and communication technology. The missions of journalism \& communication education are to cultivate journalists and other communication related workers with strong social responsibilities, and the education format and faculty structure should be relevant to the education goals.

\section{The Realistic Context of the Journalism \& Mass Communication Education}

2.1 Three Kinds of Issues to Confront. The journalism \& mass communication education need to deal with three kinds of issues: to balance theory and practice, discipline identity and the influence of globalization.

2.1.1 The Balance between Theory and Practice. The issues of theory and practice have been a controversial topic for a long time. There are prolific teaching content and powerful practical feature in the course of the journalism \& mass communication education.

Students with more practical skills are more likely to be hired [1]; however, the income and the social position are low usually, and they are also less opportunity to promotion because the graduates are lack of speculative thinking and criticism.

2.1.2 The Discipline Identity Issue. The issue of discipline identity relate to the academic life of the subject and the effect of teaching progress. About the journalism \& mass communication involve numerous disciplines, for instance, philosophy, political science, economics, law science, sociology and cultural anthropology etc. But the integration of multi-discipline also causes that the discipline and the researchers of comparative education are frequently encountered with crisis of the identity.

2.1.3 The Influence of Globalization. With the development of culture globalization, the multi-culture approves and conflicts mutually in the global scope flowing. With the influence brought by the tension and attraction of globalization and localization, the journalism \& mass communication education study has been facing unprecedented challenges.

One of the responses to the challenges is the deep change of research paradigm of journalism \& mass communication education study. The curriculum, teaching materials, teaching forms of many other countries and regions use the US as a reference. Borrowing the experience of the US, but should not simply "Americanization", we should stand on the conditions of local an build a new educational pattern which fits for the demands of local social development. 


\subsection{The Interaction between the Journalism\& Mass Communication Education and Academic Research}

2.2.1 Improving the Academic Position. Through these widespread academic research and exchanges, such as establishing multilateral international cooperative research center, publishing high level research papers, sending backbone teachers to participate in profession training and academic conference and studying and reflecting on all of significant social issues, the academic position of the journalism \& mass communication has been greatly strengthened and improved in the international academic circles.

2.2.2 Enriching the Teaching Context. The teachers of these courses combine their academic research work with the reform in teaching content and methods, enrich their teaching with the results of their scientific research, and conduct instruction by integrating academic research and teaching [2].

The interaction not only gave humanistic spirit to journalism \& mass communication education, but also made people attach importance to the media literacy education. As well, it promoted the professionalization process of news career. For example, when realizing creative learning based on blended learning pattern, the instructional design of learning activity, learning context and communication should be worked out at corresponding stages.

2.2.3 Building Sharing Platform for University Exchange. Through the research management in constructing the institutional repository, can prompt storage academic research is produced in a great number of outstanding academic research information resources for the scientific research personnel, science research, build sharing platform for journalism \& mass communication school research work provide good scientific information services.

The teachers of journalism\& mass communication can introduce scientific research projects into experimental teaching, promoting a benign cycle between experimental teaching and scientific research. Academic research renewals teachers teaching notion who take part in the experiments, improve level of academic research, and accelerate specialty development of teachers.

\section{Some Feasible Suggestions to the Development of the Journalism \& Mass Communication Education in Future}

3.1 Changing the Educational Orientation of Media Categories. Any deviation of value-orientation may result in wrong doing in the implementation of education. It has been formed the educational orientation of media categories in the journalism \& mass communication education for a long time [3].

As the expanding of the media integration, the traditional educational orientation has not been well adapted to the new development needs. It is inevitable to choose interaction, multiplex symbiosis idea and subject integration in the development of the journalism \& mass communication education.

3.2 Emphasizing both on Practice and Academic Field. Journalistic practice is an important link in journalistic education. The missions of journalism and communication education are to cultivate journalists and other communication related workers with strong social responsibilities, and the education format and faculty structure should be relevant to the education goals [4].

It put forward that only to follow the school-running law of journalism \& mass communication education, further integrate resources, adjust structure, strengthen the construction of software and hard ware, and improve teaching quality, can we realize the sustainable development of journalism \& mass communication education.

The journalism \& mass communication education should be developed on the basis of further re-searches into the basic theories, without which the science couldn't have great vitality and be highly competitive. Students who learn only theoretical knowledge without practice will be stuck in a dilemma, and fail to accomplish the assignment efficiently.

3.3 Undertaking the Responsibility of the Citizen Media Literacy. There are two aspects of media literacy education; how to understand, distinguish, and obtain the information knowledge of 
media and how to make use of media to perfect individuals. The topic of media literacy should be aroused wide spread concern in academic circles.

The media literacy education starting point should be protecting their gracious culture and society mainstream value. Presently, the government, the educational circles and the academic world should make joint efforts to promote medium literacy education among citizens. The journalism \& mass communication schools can offer elective courses, teaching material and literacy lectures for public to improve their media literacy.

3.4 Cultivating Collaboration and Teamwork. e journalism \& mass communication education put forward a team-based teaching reform to improve the student's ability in practice. Some research results are the summaries of teacher's personal experiences, which lack depth and range, and which are of little practical value when popularized.

Under this media integration background, the pattern of teaching and scientific research have produced new change, consequently, the team mode has received attention which integrated by different disciplines to do scientific and teaching research and it has made a great development.

With the rapid development of communication technology, interdisciplinary cooperation and communication are becoming more and more popular. Scientific research needs disciplinary crossing and research cooperation, and the disciplinary crossing and research cooperation require the realizing of the free movement of the faculty and researchers, resource integration and sharing.

Under the current university personnel affair management system, as the personal assessment and motivation and the administrative management relation of faculty and research personnel are fixed in a certain college or department, the disciplinary crossing and research cooperation are severely restricted.

\section{Summary}

The journalism \& mass communication education is considered as an interactive and dynamic process and demonstrates opening and diversified characteristic. The journalism \& mass communication education has got quite a lot of accomplishments in academic research, discipline development, further education and science popularization, and staff quality and public media literacy promotion.

It sums up some feasible suggestions to the development of the journalism \& mass communication education in future, such as changing the educational orientation of media categories, emphasizing both on practice and academic field, taking the responsibility of the citizen media literacy and cultivating collaboration.

\section{Acknowledgements}

This research was financially supported by the Educational Research Foundation of Wuhan Textile University (Grant NO. 2016JY024) and Educational Research Foundation of Wuhan Textile University (Grant NO. 201605024).

\section{References}

[1] E.M. Rogers and S.H. Chaffee: J. Commun. Vol. 43 (1993), p. 128.

[2] R.O. Blanchard and W. G. Christ: Journalism Educ. Vol. 36 (1985), p. 29.

[3] D. McQuail, in: Mass communication theory, edtied by SAGE Publications, London (2000), in press.

[4] W. Brandon: Journalism \& Mass Comun. Educ. Vol. 57 (2002), p. 64. 